ARTICLE

DOI: $10.1057 /$ s41599-017-0046-8

\title{
How to communicate effectively with policymakers: combine insights from psychology and policy studies
}

\author{
Paul Cairney ${ }^{1} \&$ Richard Kwiatkowski ${ }^{2}$
}

\begin{abstract}
To communicate effectively in policymaking systems, actors need to understand how policymakers process evidence and the environment in which they operate. Therefore, we combine psychology and policy studies to produce a three-step strategy. First, do not bombard people with evidence. Human beings have too much information to process, and they use heuristics to filter information to make decisions quickly. Synthesise and frame evidence to help you tailor it to the ways in which policymakers demand and understand information. Second, find the right time to act. Timing matters during key individuals' patterns of thinking and the alignment of conditions in political systems. Third, engage with real world policymaking rather than waiting for a 'rational' and orderly process to appear. To present evidence during mythical stages of a 'policy cycle' is misguided, and to 'speak truth to power' without establishing legitimacy and building trust may be counterproductive. Our overall message is pragmatic, not Machiavellian: effective communication requires the suppliers of evidence to see the world from the perspective of their audience and understand the policy process in which they engage.
\end{abstract}

\footnotetext{
${ }^{1}$ Division of History and Politics, University of Stirling, Stirling, UK. ${ }^{2}$ Cranfield School of Management, Cranfield University, Cranfield, UK. Correspondence and requests for materials should be addressed to P.C. (email: p.a.cairney@stir.ac.uk)
} 


\section{Introduction: use psychology and policy theory to improve communication}

olicymakers cannot pay attention to all the things for which they are responsible, or process all of the information they could use to make decisions. Like all people, there are limits on what information they can process (Baddeley, 2003; Cowan, 2001, 2010; Miller, 1956; Rock, 2008). People use short cuts to gather enough information to make decisions quickly: the 'rational', by pursuing clear goals and prioritising certain kinds of information, and the 'irrational', by drawing on emotions, gut feelings, values, beliefs, habits, and the familiar, to make decisions quickly.

We use the term 'irrational' provocatively, to criticise an oftenexpressed sense that 'fast thinking' hinders the use of evidence in policy: the fairytale that heroic scientists are thwarted by villainous politicians drawing on their emotions and deeply held beliefs in a 'post truth' world (see Jasanoff and Simmet, 2017). Rather, policymakers face unusually strong and constant pressures on their cognition and emotion. They need to gather information quickly and effectively, often in highly charged political atmospheres, so they develop heuristics to allow them to make what they believe to be good choices. Perhaps their solutions seem to be driven more by their values and emotions than a 'rational' analysis of the evidence, often because we hold them to an information processing standard that no human being can reach. If so, and if they have high confidence in their heuristics, they may dismiss criticism of their decision-making process as biased and naïe. Under those circumstances, repeatedly stating the need for 'rational' and 'evidence-based policymaking' is pointless, and naively 'speaking truth to power' counterproductive.

Our alternative approach is to develop ways to engage positively while recognising that the limits to evidence-based action and cognitive biases we ascribe to policymakers are also present in ourselves, our own groups, and the people we often describe as experts (Perez, 2015; Cassidy and Buede, 2009). ${ }^{1}$ Rather than decry cognitive biases in one's political opponents, it is more helpful to acknowledge their universal existence (Houghton, 2008). It can be deeply counterproductive to use unpleasant euphemistic terms like 'low information' to describe actors whose views we do not respect. This is a particular problem for scholars if they assume that most people do not live up to their own imagined standards of high-information-led action while actually using similar shortcuts to reinforce and bolster their own beliefs (Gregg et al., 2016).

Instead, we synthesise a wealth of knowledge from studies of psychology and policy theory to produce a more effective threestep communication strategy:

1. Understand your audience. To help tailor your approach to the cognitive processes present in human beings, synthesise evidence concisely to minimise its cognitive burden, and 'frame' your conclusions rather than expecting evidence to speak for itself.

2. Identify the right time to exploit 'windows of opportunity'. 'Timing' can refer to the right time to influence an individual, depending on their current way of thinking, or to act while the political conditions are just right.

3. Engage with real world policymaking rather than waiting for a 'rational' and orderly process to appear. To present evidence during mythical stages of a 'policy cycle' may be misguided, and to 'speak truth to power' without establishing trust in networks and an open culture in organisations may be counterproductive.

These steps are complementary and interconnected rather than a suite of options from which to choose one. They help produce pragmatic, not manipulative, communicators. We do not argue that policymakers have unusual cognitive biases or that we should use psychological insights or bend evidence to trick politicians. Rather, these steps help foster the clearer communication of policy-relevant evidence to any relevant audience. Further, it is useful to work on the assumption that people's beliefs are honestly held, and policymakers believe that their role is to serve a cause greater than themselves. Indeed, we often elect politicians so that they can use their values to make difficult moral choices on our collective behalf. Or, someone seeking to encourage more powerful people to change course may need to run alongside them, in the same direction, at least for a while, before pointing out that better paths exist. This involves showing simple respect and seeking ways to secure their trust, rather than feeling egotistically pleased about 'speaking truth to power' without discernible progress. Effective engagement requires preparation, diplomacy, and good judgement as much as good evidence.

\section{Key insights from psychology and policy theory}

For decades, policy theories have used the phrase 'bounded rationality' to describe the limits to our cognitive power: as human beings, policymakers do not have the time, resources or cognitive capacity to consider all information, all possibilities, all solutions, or anticipate all the consequences of their actions (Simon, 1976; Cairney and Heikkila, 2014). People are 'cognitive misers' (Kam, 2005), using informational shortcuts and heuristics to gather just enough information to make decisions.

More recently, policy scholars have drawn heavily from psychology to understand how emotions act as informational shortcuts, and coexist with cognition in individual and group thinking. Direct reference points from psychology include:

1. Haidt's (2001, p 818; 2007, 2012) distinction between 'intuitive system' and 'reasoning system'. People grasp moral truths as a form of perception, not reflection, and 'moral reasoning is usually an ex post facto process used to influence the intuitions (and hence judgements) of other people'; one has an instant gut response to certain issues and 'when faced with a social demand for a verbal justification, one becomes a lawyer trying to build a case rather than a judge searching for the truth' (Haidt, 2001, p 814).

2. Kahneman's (2012, p 20) thinking 'fast and slow': 'System 1 operates automatically and quickly, with little or no effort and no sense of voluntary control. System 2 allocates attention to the effortful mental activities that demand it, including complex computations ... often associated with the subjective experience of agency, choice and concentration'.

For example, Lewis (2013, p 4, p 7) argues that 'fast' thinking is 'typically where the action is' because people tend to conserve 'attention and cognitive processing capabilities for the few activities we currently view as most essential' and rely on 'autopilot' whenever emotions are heightened. He describes a list of cognitive shortcuts, derived from psychology studies, that are now a key feature of policy scholarship, including:

- the 'availability heuristic', when people relate the size, frequency or probability of a problem to how easy it is to remember or imagine;

- the 'representativeness heuristic', when people overestimate the probability of vivid events;

- 'prospect theory', when 'losses tend to pain us more than gains please us'; 
- 'framing effects' based on emotional and moral judgements over well thought out preferences;

- 'confirmation bias', where material that corroborates what we already believe is given disproportionate credence;

- 'optimism bias', or unrealistic expectations about our aims working out well when we commit to them;

- 'status quo bias';

- a tendency to use exemplars of social groups to represent general experience; and,

- a 'need for coherence' to establish gestalt like patterns and causal relationships when they may not exist (2013, p 7).

There is always more to learn from contemporary psychological studies which 'zoom in' to key aspects such as individual and organisational psychology. For example, processing fluency (built on studies of the availability heuristic) suggests that individuals' decisions are influenced by their familiarity with things; and with the ease in which they process information (Alter and Oppenheimer, 2009). They may pay more attention to an issue or evidence if they already possess some knowledge of it and find it relatively easy to understand or recall (Alter and Oppenheimer, 2009, p 220). Other studies focus primarily on emotional heuristics (Brader, 2011; Haste, 2012), analyse the emotional connection of individuals to the groups to which they identify (Menges and Kilduff, 2015), or otherwise recognise that emotion and cognition are part of the same internal mental process (Storbeck and Clore, 2007).

Organisational psychology highlights the importance of 'social context' and 'group processes', which often inhibit an organisation's ability to 'liberate' the knowledge provided by each person and broaden the 'information considered before making a decision' (Larrick, 2016). Obstacles include a tendency in established groups to share, repeat, and trust 'commonly held' rather than new information ('common knowledge bias'), and to minimise disagreement by limiting the diversity of information, which disadvantages outsiders or "people in low positions of power who withhold their private doubts because they fear a high social cost' (2016, p 448).

Empirical studies are rarely conducted on policymakers directly (Kwiatkowski, 2016), but the implications can be profound. In particular, a policymaker may feel antagonism towards a person giving what they perceive to be dubious evidence without realising that is because they are 'carrying' a group emotion with them (Menges and Kilduff, 2015). One's lack of awareness of the emotion does not preclude action (Schein, 1969). For example, Van Stekelenburg and Klandermans (2013) point to the need for collective social identification, a sense of collective self-efficacy and the presence of emotion as predictors of coordinated political action (such as protest). Kam (2005) found that actors draw more from cues related to their allies (such as a shared political party) than specific political issues. Houghton (2008) points to many 'errors'-from 'decision making on impulse' to 'groupthink'-that the Bush administration made when going to war in Iraq, and the Chilcot Inquiry (2016) makes similar points about the UK Government under Blair. More generally, Bion (1961) contrasts the positive idea of a work group, or group of individuals able to have a good contact with reality and deal with the anxiety engendered by complex tasks or difficult relationships, with a maladaptive group that seems to be in the thrall of unspoken and unconscious 'basic assumptions' and fairly closed to logical arguments.

The added value of policy studies is to show how such individual and group behaviour plays out in complex policymaking environments, containing:

1. A large number of influential actors spread across fragmented and multi-level political systems.
2. Institutions, as the rules and norms that actors use as shortcuts to action.

3. The networks between policy makers and influencers, often built on regular exchanges of information, trust, and a shared outlook.

4. A tendency for well-established beliefs to monopolise the ways in which actors understand policy problems.

5. The routine or unanticipated events to which policymakers pay attention.

6. The socioeconomic context, to which policymakers need to respond, even if most policy conditions (such as demographic and economic change) are difficult to fully understand or remain out of their control (Cairney and Heikkila, 2014; Cairney and Weible, 2017).

In other words, modern policy theories take us beyond simple notions of linear policymaking via a series of stages in a policy cycle, in which: a small elite group of policymakers are in control of the policy process; they are aided by expert policy analysts to make and legitimise choices; skilful public servants carry them out; and, policy analysts assess the results using evidence (Cairney, 2015; 2016). Instead, there are many powerful but boundedly rational actors in play. Individual policymakers, or a collection of elite policymakers at the 'macropolitical' level, can only 'serial process', or focus on one issue at a time; governments as a whole can 'parallel process' because there are many policymakers spread across many organisations working on different issues (Baumgartner and Jones, 1993, p 7). In such a complex system, where no single policymaker is in charge, and policy outcomes seem to emerge without singular central direction: 'the most relevant evidence adopters will be operating at multiple levels of government, stages will appear to interact in a disorderly way, and policy will be made as it is carried out, by bodies that may not report directly to central government' (Cairney, 2016, p 41; Cairney, 2012b).

Early post-war studies focused on the goal-oriented strategies of key actors in that context (Jones, 2017). Simon (1957; 1976, p 28) identified policymakers' 'rules of thumb' to identify the issues most important to them and gather the most relevant information to produce 'good enough' decisions. For Lindblom (1959, p $88 ; 1964, p$ 157) 'incrementalism' described key rules to deal with bounded rationality: identify realistic policy aims that do not divert radically from the status quo, limit analysis to those options, and combine analysis with strategies such as trial-anderror. Their enduring insight is that bounded rationality is an ever-present constraint on policymakers, who are 'under continual pressure to reach decisions' (Botterill and Hindmoor, 2012, p 369). Although information technologies have improved, they do not preclude the need to make judgements quickly about "what is feasible' in the face of limits to 'brain power, time and financial inputs' (2012, p 369).

Modern theories show that 'incremental' change may result less from strategic trial and error and more from unequal power; the exercise of power to entrench fast choices. Policymakers respond to bounded rationality by relying on quick gut-level, instinctual, emotional, and moral choices. Put most strongly, 'Reason is emotion's slave and exists to rationalize experience' (Bion, 1970) when unconscious processes, out of awareness, are present (Arnaud, 2012). 'Hot cognition' (Lodge and Taber, 2005, p 456) describes actors' feelings about things they have thought about in the past - 'political leaders, groups, issues, symbols, and ideas' which come 'automatically and inescapably to mind' and 'become information'. If so, people become 'biased reasoners ... even when they are motivated to be impartial'. Passion and intuition helps explain why policymakers quickly assign praise and blame to 'target populations' and their beliefs often seem impervious to 
change (Schneider et al., 2014; Lewis, 2013, p 13; Fiske 2011). Policy actors may deal collectively with bounded rationality by telling simple stories to help "process information, communicate, and reason' (McBeth et al., 2014) and an 'evidence-gathering' process may serve to reinforce collective identity or what people already believe (Lewis, 2013, p 13-15; Stone, 1989). Or, powerful 'advocacy coalitions' can obstruct policy change for decades (Jenkins-Smith et al. 2014). They consist of actors who enter politics to turn their beliefs into policy, form coalitions with people who share their beliefs, romanticise their own cause and demonise their opponents (Sabatier et al., 1987, p 451; Buckingham, 2011), and interpret the same evidence in wildly different ways (Weible, 2007, p 99).

However, bounded rationality can also prompt major policy change. Individuals typically pay attention to one policy problem and a particular way to frame it (the 'policy image') at a time. They often take certain ways of thinking for granted for long periods, often because they are not paying attention (Baumgartner and Jones, 1993, p 7; Baumgartner, 2017; Cairney, 2012a, p 230; Hall, 1993). Yet, policy problems are ambiguous, people can entertain multiple policy images (Zahariadis, 2014), and a small change in policy conditions, or injection of new information, can produce a major shift of attention to a policy problem or different image (Baumgartner et al., 2014). Bounded rationality plus ambiguity produces the potential for 'macro-political' attention to lurch dramatically and create the conditions for change (True et al., 2007, pp 158-159). During such 'windows of opportunity', actors can exploit widespread but temporary surges of attention to a problem to promote their favoured solution (Kingdon, 1984; Zahariadis, 2014; Cairney and Jones, 2016).

\section{Use this knowledge to produce a three-step communication strategy}

We can choose to describe such informational shortcuts negatively or positively. For example, it is common for studies of 'evidence based policymaking' to bemoan the cognitive biases of policymakers and seek ways to limit individual discretion (Cairney, 2016, p 123; Parkhurst, 2016). Yet, how could elected policymakers possibly understand all of the things for which they are responsible, or produce a coherent and orderly policy process when so many actors, institutions, networks, ideas, events, and socioeconomic conditions are in play?

Gigerenzer (2001, pp 37-38) makes a more positive case for human cognition under such complex conditions, describing heuristics as the 'computationally cheap' methods people use to make choices, as part of an 'adaptive toolbox'. He argues that we should understand 'how actual humans ....make decisions, as opposed to heavenly beings being equipped with practically unlimited time, knowledge, memory, and other unlimited resources'. In other words, examine how people use 'fast and frugal' heuristics and emotions to limit choice. These tools allow people to experiment using trial and error, use emotions to limit needless searches for new choices (such as considering the costs/ benefits of keeping one's children), and make choices based on a small number of simple rules rather than trying in vain to weigh all costs and benefits (see also Frank, 1988). It is not necessary to marvel at policymaker heuristics, but a less negative interpretation allows us to think about how to respond positively.

\section{Step 1. Understand your audience and tailor your response}

The first step is to consider 'cognitive biases' from the perspective of policymakers instead of bemoaning them from our own: while we may think they take policymaking 'off course', they envisage a bias in a road which allows them to travel smoothly and safely around a sharp bend. Policymakers have to make decisions quickly, often based on their values and judgements reflecting their beliefs. New data triggers schemata in the brain that 'filter out' the need to pay complete attention, by, for example, recognising a familiar array of circumstances. This process of skilled high-level pattern recognition may override what we consider to be an impetus to act differently when new facts arise.

On that basis, we can tailor responses with reference to fluency, conscious action, emotional decision-making, and evolutionary psychology. First, from studies of processing fluency we already know to avoid overly complicated presentations of evidence with numerous subclauses, technical diagrams, caveats, nuances, and academically fashionable jargon. Studies of learning (Winne and Nesbit, 2010) suggest: minimising cognitive load and the amount of material to be stored in temporary short term memory; creating conditions for transfer to long term memory; using multiple coding (such as words and pictures); presenting materials more than once; maintaining coherence of the message; minimising the irrelevant; telling stories and giving specific examples; asking for feedback; providing time for processing and reflection; and attending to energy and fatigue levels.

We could also consider factors such as primacy and recency, in which material presented at the beginning or at the end of a presentation is more likely to be recalled, and the Von Rostroff effect, in which something unusual becomes more memorable. Studies also point to strategies such as the manipulation of fonts, colours, and duration of texts and images, the repeated use of text or images, or the simplification of messages, or provision of priming messages, to influence their recall and ease of information processing; and the provision of fewer choices to aid decision making (Alter and Oppenheimer, 2009, p 227). Communication can also grab the attention using focusing events (Birkland, 1997), linking evidence to something immediate that affects them - or their voters or party-and generating a sense of proximity to an issue that can be perceived in concrete, not abstract, terms (Alter and Oppenheimer, 2008, p 166).

Second, policymakers who use deliberate tactics consciously may need to be consciously influenced. For example, to reflect Simon and Lindblom's insights, actors need to identify the visible goals expressed explicitly by policymakers, and the less visible 'rules of thumb' they use to deal with bounded rationality and make 'good enough' decisions quickly.

Third, it is less obvious how to adapt to, or try to influence, people motivated by social intuition, values or moral judgement, and we need more evidence on the success of specific adaptation strategies. However, studies of 'framing' provide a starting point. In policy studies, 'framing' or 'problem definition' refers to the ways in which we encourage our audience to understand, portray, and categorise issues. Problems are multi-faceted, but bounded rationality limits the attention of policymakers, and actors compete to highlight one image at the expense of others. The outcome of this competition determines who is involved, who has relevant expertise, who is responsible for policy, how much attention they pay, and what kind of solution they favour (Baumgartner and Jones, 1993; Dearing and Rogers, 1996).

In that context, we should adapt framing strategies specifically to the cognitive biases we think are at play (Cairney et al., 2016, p $3)$. If policymakers are combining cognitive and emotive processes, combine facts with emotional appeals (True et al., 2007, p 161). If policymakers are reflecting a group emotion, frame new evidence to be consistent with the 'lens' through which actors in those groups or coalitions understand the world (Weible et al., 2012). If policymakers are making quick choices based on their values and moral judgements, tell simple stories with a hero and a clear moral (see the articles on storytelling in the Palgrave Communications series, by Davidson, 2017 and Jones and Crow 2017). 
Finally, a fundamental aspect of evolutionary psychology is that people need to get on with each other, so showing simple respect - and 'mirroring' - can be useful even if it looks facile. Indeed, there is good evidence to show that stepping into someone else's shoes allows you to more fully appreciate their world from their position (De Vignemont \& Singer, 2006).

\section{Step 2. Identify 'windows of opportunity'}

Timing matters, but it can refer to two very different processes. In psychology, timing can refer to the often-limited chance to influence individuals. An emotional reaction may take place before any conscious processing, and the person may not be aware that their decision is not made purely on logical grounds. For example, clear thinking is difficult during extended heightened emotion (say, during an important event). Anyone seeking to influence policymakers at such times should note that it is unlikely that peripheral information will be attended to or remembered, since it may not even enter 'working memory' (Baddeley, 2012). What is seen as crucially important may absorb all the processing capacity of an individual; if that individual is under stress and the arousal lasts a long time the effect may be pronounced. However, under some conditions of heightened arousal, memory may not function the way you expect. For instance, 'flashbulb memory' may occur for particular events, and people may remember peripheral or irrelevant material extremely vividly (as in the triggering cues for posttraumatic stress disorder).

It is possible to find the right time to influence emotional thinking while, for example, telling vivid stories to arouse the emotional interest of your audience. However the emotional content of the communication can have a perverse effect. For example, health psychology studies find that, under certain conditions, if the suggested outcome-such as terror at dying of cancer as a result of smoking-is portrayed too vividly, or is too frightening, people may 'switch off', exhibiting defensive reactions rather than attend to the message (Witte \& Allen, 2000). There seems to be a $U$ shaped curve of attention when it comes to the vividness of emotional messaging (Dillard et al., 2016).

It may be more effective to provoke positive emotions by setting a positive 'emotional tone' using, for example Cialdini's (1983) notion of social proof to indicate how many other members of a favoured social group share a particular position. However, someone's pre-existing emotional attachment or allegiance to a group or coalition may rapidly override any positive feelings they have towards you or your position. In other words, it is useful to bear in mind the broader system within which this human being is embedded. Foulkes and Anthony (1957) describe people being nodes in an emotional net; as part of the net is tugged the node or knot moves. You may cause some slight movement but remember the existing interconnections to others may be much more powerful than your tug. In short, storytelling matters, but your evidence-based story may compete with the stories that people tell themselves about themselves and their place in the world (Tuckett and Nikolic, 2017).

In policy studies, timing refers to the dynamics of policy environments. For example, multiple streams analysis describes the conditions under which there is a 'window of opportunity' for policy change: attention to a policy problem rises; a feasible solution exists; and, policymakers have the motive and opportunity to select it (Kingdon, 1984; Zahariadis, 2014; Cairney and Jones, 2016). So, framing problems is an important exercise, but lurches of attention to one way of understanding a problem won't produce policy change unless a solution has become acceptable to the wider policy network and policymakers identify the right time to act.
Kingdon (1984, p 21, p 104) describes 'policy entrepreneurs' who use their knowledge of this process to further their own policy ends. They 'lie in wait in and around government with their solutions at hand, waiting for problems to float by to which they can attach their solutions, waiting for a development in the political stream they can use to their advantage' (Kingdon, 1984, p 165-166; Cairney, 2012a, pp 271-272). Note the primacy of environmental conditions in this metaphor: entrepreneurs are 'surfers waiting for the big wave' (Kingdon, 1984, p 173), not 'Poseidon-like masters of the seas' (Cairney and Jones, 2016, p 41). Their effectiveness comes from an investment of resources to generate knowledge of the political system and its 'rules of the game', build up trust in the information they provide, and form coalitions, all of which helps them know when to act decisively when the time is right.

\section{Step 3. Engage with real world policymaking rather than waiting for a 'rational' and orderly process to appear}

If the policy process does not resemble a policy cycle in which we know to whom and when to provide evidence, we need more intelligent strategies to engage with real world policymaking. It is tempting to argue that policymaking should change to encourage more use of scientific evidence (Parkhurst, 2016), but we can also be pragmatic enough to adapt our own strategies while we wait for it to happen (or expect it never to happen, Cairney, 2016).

We can infer from the organisational psychology literature that this wait will be long. For example, the study of leadership in organisations is vast and inconclusive (Avolio et al. 2009; Lewis \& Donaldson-Feilder, 2012). It often produces vague 'how to do it better' advice from which we can infer that organisations are not already doing well (Bedi \& Schat, 2013; Ferris, 2005; Ferris et al., 2007; Kapoutsis, Papalexandris, Nikolopoulos, Hochwarter, \& Ferris, 2011; Prati, Perrewe, \& Ferris, 2009). 'State of the art' studies have, for decades, recommended major changes to rules and behaviour rather than reported their actual occurrence.

For example, Larrick (2016, p 461) identifies ways to encourage greater diversity of perspectives in group decision-making by fostering trust, collectivism, and an assurance that less powerful or more peripheral actors are not punished for presenting information that challenges existing ways of thinking. One solution is 'task conflict' rather than 'relationship conflict', to encourage information sharing without major repercussions. It requires the trust and 'psychological safety' that comes with 'team development' (2016, p 448). If successful, one can 'speak truth to power' (Wildavsky, 1980) or be confident that your presentation of evidence, which challenges the status quo, is received positively. Under such circumstances, a 'battle of ideas' can genuinely take place and new thinking can be possible.

If these circumstances are not present, speaking truth to power may be disastrous. Politicians may be confident of policy and have an impressive grasp of facts and details, but be only adequate in organisational politics, or unable to change the rules of their organisations (Kwiatkowski, 2011). Or, while they necessarily appear highly confident, they are actually vulnerable, anxious, and defensive, and perhaps closed to challenging or discordant information.

Consequently, our aim is to give advice to actors who need to adapt to current organisational reality even if they hope they can help change it in the long run. In the absence of Larrick's suggested reforms, actors need different strategies, such as: form relationships in networks, coalitions, or organisations first, then supply challenging information second. To challenge without establishing trust may be very counterproductive, and lead to outright premature rejection; and, once a public position has been taken, it is particularly difficult for policy to be reversed. 
Such general advice is already common in policy studies as part of a package of possible measures: "learn and follow the "rules of the game" [of policy networks] to improve strategies and help build up trust; form coalitions with actors with similar aims and beliefs; and frame the evidence to appeal to the biases, beliefs, and priorities of policy makers' (Cairney et al., 2016; see also Weible et al., 2012; Stoker 2010, pp 55-57). From organisational psychology, we may develop further analysis of how to identify chances to form networks with, or influence, policymakers, such as being at the right place at the right time and having influential mentors (Kwiatkowski, 2011). This knowledge may help practitioners to spot the difference between:

1. people in organisations who have limited power, have been asked to fill in time for others, and/ or will not spend what little political capital they possess in championing your position

2. the more astute, who will have identified your issue as an upcoming problem, an area where they can demonstrate thought leadership, become the acknowledged expert, or even save the group from a terrible decision.

With the latter, you are pushing at an open door but you may need to put aside your own ego and allow them to take over and express your ideas. You may even want to write parts of their speeches for them, provide them with briefings, and (if you are lucky) allow them to have the kudos of having an expert on tap. Here you are putting yourself in the role of a 'follower', in the hope that leaders will remember and reward you. In other words, leader member exchange theory would suggest that some reciprocity would be expected on both sides (Kwiatkowski, 2011). Of course it is risky to ally yourself with one side, but somewhat riskier to think of yourself, naïvely, as above organisational politics. The more you are aware of internal political groupings in the institution you are seeking to influence the better. At the very least, by attending to the signals from specific groups you can make sure that you are positioning your message appropriately.

\section{Conclusion}

To engage effectively in policymaking, we need to understand that it is not populated by a small number of elite, 'rational' actors making policy in a series of linear stages. Rather, human psychology and political systems come together to create a dynamic policy process characterised by many actors combining cognition and emotion while competing to influence continuous policy choice. The role of evidence is not always clear. However, the policy literature emphasises its use more than its production, by actors who anticipate or respond to lurches of attention, moral choices, and coalitions built on bolstering one's own position, demonising competitors, and discrediting some evidence. Such analysis provides a useful corrective to the fantasy of a logical, understandable, controlled, linear policy process in which evidence can be directed to a single moment of authoritative and 'comprehensively rational' choice.

These insights help us develop three profoundly important lessons. First, use psychological insights to 'know your audience'. People combine cognitive and emotional short cuts to thought and action, and they often do so without fully understanding the underlying reasons for their action. So, presenting a concise evidential synthesis to minimise cognitive burden is more effective than bombarding them with more information than they are willing and able to process. Further, telling stories, or using other framing techniques that more readily allow information to enter the memory, is more effective than presenting evidence as if it can speak for itself. Evidence advocacy is ineffective if focusing purely on logic, 'establishing the facts', or describing complexity in an overly complicated way, rather than building on the ways in which people simplify their world. Framing and storytelling helps policymakers understand why they should pay attention to a problem, and prompts them to demand more evidence to help solve it.

Second, understand the role of timing. It is possible to find the right time to influence thinking by telling stories to arouse the emotional interest of your audience, but clear thinking is difficult during extended heightened emotion; the emotional content of the communication can have unintended consequences, and it may be more effective to set a positive emotional tone with reference to the beliefs of an individual's favoured social group. In policymaking systems, timing relates more to the confluence of events and choices: attention rises to a problem, a solution is available, and key actors have the motive and opportunity to select it.

Third, do not wait for a 'rational' and orderly process to appear. To try to present evidence during mythical stages of a 'policy cycle' is misguided, and to 'speak truth to power' without establishing trust is counterproductive. To understand the dynamics of policymaking organisations and systems requires major investment. Policymaking takes place in an environment with many policymakers, many authoritative organisations, venues, or networks with their own rules that take time to understand, and in which there is often a dominant way to understand policy problems. So, evidence may have little impact unless we work out which coalitions hold influence, how their members understand the world, where and with whom to engage, how to form effective alliances, and how to spot the right time to act.

Of course, there remain ethical questions about how far we should take this advice (Cairney and Oliver, 2017; Smith and Stewart, 2017; Cairney and Weible, 2017). It may look like we recommend a shift from 'honest broker' to 'issue advocate', which often seems counter to a scientific identity (Pielke, 2007). Rather, most of our advice is simply to promote clearer communication based on knowing your audience and the environment in which they operate. We can only make a careful judgement about going further if we clarify the strategies available to us, and reflect on our reasons for action in relation to our own ethical and moral positions.

Received: 3 May 2017 Accepted: 15 November 2017 Published online: 28 November 2017

\section{Notes}

1 Indeed, we have to make our recommendations while facing our own cognitive and evidential limits. At best, much of this psychological research is nascent, producing a limited evidence base that is difficult to replicate in messy, multivariate and complex real-world political contexts. Further, within psychology, the idea of the 'normal' human being does not command widespread support, so all generalisations about the underpinnings of patterns of cognition should always be treated with caution. Policy scholars have used psychological insights to inform theories effectively, but in a speculative or deductive way not anticipated by the original architects of psychological research. In most cases, the original research informs one aspect of a new problem without giving us much indication about what to do, and at times it does little to inform ethical discussions about how we should act, since many psychologists are interested in understanding what is rather than speculating on what should be. So, this article and its recommendations represent 'the psychological politics of evidence-based policymaking' in a nutshell: policymakers face uncertainty and have to draw on limited evidence, and make value judgements, to produce necessarily problematic but 'good enough' decisions. If we seek to influence that process we may need to do the same, even if our potentially successful strategies are not as 'evidence based' as we would like. If we embrace this need to act pragmatically and humbly, despite high uncertainty, 'psychology based policy studies' will become a central component of any policy 'impact' initiative. 


\section{References}

Alter A, Oppenheimer D (2008) Effects of fluency on psychological distance and mental construal. Psychol Sci 19(2):161-167

Alter A, Oppenheimer D (2009) Uniting the tribes of fluency to form a metacognitive nation. Personal Social Psychol Rev 13(3):219-235

Arnaud G (2012) The contribution of psychoanalysis to organization studies and management: an overview. Organ Stud 33(9):1121-1135. https://doi.org/ $10.1177 / 0170840612448153$

Avolio BJ, Walumbwa FO, Weber TJ (2009) Leadership: current theories, research, and future directions. Annu Rev Psychol 60:421-449

Baddeley A (2003) Working memory: looking back and looking forward. Nat Rev Neurosci 4(10):829-839. https://doi.org/10.1038/nrn1201

Baddeley A (2012) Working memory: theories, models, and controversies. Annu Rev Psychol 63(1):1-29. https://doi.org/10.1146/annurev-psych-120710-100422

Baumgartner F (2017) Endogenous disjoint change. Cogn Syst Res 44:69-73

Baumgartner F, Jones B (1993) Agendas and instability in American politics, 1st edn. Chicago University Press, Chicago, IL

Baumgartner F, Jones B, Mortensen P (2014) Punctuated-equilibrium theory: explaining stability and change in public policymaking. In: Sabatier P, Weible C (eds) Theories of the policy process, 3rd edn. Westview Press, Chicago

Bedi A, Schat ACH (2013) Perceptions of organizational politics: a meta-analysis of its attitudinal, health, and behavioural consequences. Can Psychol/Psychol Can 54(4):246-259. https://doi.org/10.1037/a0034549

Bion WR (1961) Experiences in groups and other papers. Tavistock Publications, London

Bion WR (1970) Attention andInterpretation: a scientific approach to insight in Psycho-Analysis and Groups (First). Tavistock Publications, London

Birkland T (1997) After disaster: agenda setting, public policy, and focusing events. Georgetown University Press, Washington, DC

Botterill L, Hindmoor A (2012) Turtles all the way down: bounded rationality in an evidence-based age. Policy Stud 33(5):367-379

Brader T (2011) The political relevance of emotions: "reassessing" revisited. Political Psychol 32(2):337-346. https://doi.org/10.1111/j.1467-9221.2010.00803.x

Buckingham, L. (2011) Projective identification revisited a thread in the labyrinth: returning to melanie klein's concept of projective identification. https://doi. org/10.1111/j.1752-0118.2011.01256.x

Cairney P (2012a) Understanding public policy. Palgrave, Basingstoke

Cairney P (2012b) 'Complexity theory in political science and public policy'. Political Stud Rev 10:346-58

Cairney P (2015) 'How can policy theory have an impact on policy making?'. Teach Public Adm 33(1):22-39

Cairney P (2016) The politics of evidence-based policymaking. Palgrave, London

Cairney P, Heikkila T (2014) A comparison of theories of the policy process. In: Sabatier P, Weible C (eds) Theories of the policy process, 3rd edn. Westview Press, Chicago

Cairney P, Jones M (2016) 'Kingdon's multiple streams approach: what is the empirical impact of this universal theory? Policy Stud J 44(1):37-58

Cairney P, Oliver K (2017) Evidence-based policymaking is not like evidence-based medicine, so how far should you go to bridge the divide between evidence and policy?. Health Res Policy Syst 15:35. https://doi.org/10.1186/s12961017-0192-x

Cairney P, Oliver K, Wellstead A (2016) To bridge the divide between evidence and policy: reduce ambiguity as much as uncertainty, Public Adm Rev 76(3):399-402. https://doi.org/10.1111/puar.12555

Cairney P, Weible C (2015) Comparing and contrasting Peter Hall's paradigms and ideas with the advocacy coalition framework. In: Howlett M, Hogan J (eds) Policy paradigms in theory and practice. Palgrave, London

Cairney P, Weible C (2017) The new policy sciences, Policy Sciences, 50(4):619-27. https://doi.org/10.1007/s11077-017-9304-2

Cassidy MF, Buede D (2009) Does the accuracy of expert judgment comply with common sense: caveat emptor. Manag Decis 47(3):454-469. https://doi.org/ $10.1108 / 00251740910946714$

Chilcot J (2016) Iraq inquiry report, executive summary of the report of the inquiry, vol 1

Cialdini R (1983) Influence. Harper Collins, London

Cowan N (2001) The magical number 4 in short term memory. A reconsideration of storage capacity. Behav Brain Sci 24(4):87-186. https://doi.org/10.1017/ S0140525X01003922

Cowan N (2010) The magical mystery four: how is working memory capacity limited, and why? Curr Dir Psychol Sci 19(1):51-57. https://doi.org/10.1177/ 0963721409359277

Davidson B (2017) Storytelling and evidence-based policy: lessons from the grey literature. Pal Commun, 3, 1-10. https://www.nature.com/articles/palcomms 201793

Dearing JW, Rogers EM (1996) Agenda Setting. Sage, London

De Vignemont F, Singer T (2006) 'The empathic brain: how, when and why?'. Trends Cogn Sci 10(10):435-441
Dillard JP, Li R, Meczkowski E, Yang C, Shen L (2016) Fear responses to threat appeals: functional form, methodological considerations, and correspondence between static and dynamic data. Commun Res. https://doi.org/10.1177/ 0093650216631097

Ferris GR (2005) Development and validation of the political skill inventory. J Manag 31(1):126-152. https://doi.org/10.1177/0149206304271386

Ferris GR, Treadway DC, Perrewe PL, Brouer RL, Douglas C, Lux S (2007) Political skill in organizations. J Manag 33(3):290-320. https://doi.org/10.1177/ 0149206307300813

Fiske S (2011) Envy up, scorn down: how status divides us. Russell Sage Foundation, New York, NY

Foulkes SH, Anthony EJ (1957) Group psychotherapy: The analytic approach

Frank R (1988) Passions within reason: the strategic role of the emotions. Norton, NewYork, NY

Gigerenzer G (2001) The adaptive toolbox. In: Gigerenzer G, Selten R (eds) Bounded rationality. MIT press, Cambridge, MA

Gregg AP, Mahadevan N, Sedikides C (2016) The SPOT effect: people spontaneously prefer their own theories. Q J Exp Psychol 218:1-15. https://doi.org/ $10.1080 / 17470218.2015 .1099162$.

Haidt J (2001) The emotional dog and its rational tail: a social intuitionist approach to moral judgment. Psychol Rev 108(4):814-834

Haidt J (2007) The new synthesis in moral psychology. Science 316:998-100

Haidt J (2012) The righteous mind: why good people are divided by politics and religion. Pantheon, New York, NY

Hall P (1993) Policy paradigms, social learning, and the state: the case of economic policymaking in Britain'. Comp Polit 25(3):275-96

Haste H (2012) Where do we go from here in political psychology? An introduction by special issue editor. Political Psychol 33(1):1-9. https://doi.org/ $10.1111 /$ j.1467-9221.2011.00868.x

Houghton DP (2008) Invading and occupying Iraq: some insights from political psychology. Peace Confl: J Peace Psychol 14(2):169-192. https://doi.org/ $10.1080 / 10781910802017297$

Jasanoff S, Simmet H (2017) No funeral bells: public reason in a 'post-truth' age. Social Stud Sci 47(5):751-770

Jenkins-Smith H, Nohrstedt D, Weible C (2014) The advocacy coalition framework: foundations, evolution, and ongoing research' process. In: Sabatier P, Weible C (eds) Theories of the policy process, 3rd edn. Westview Press, Chicago

Jones B (2001) Politics and the architecture of choice: bounded rationality and governance. University of Chicago Press, Chicago

Jones B (2017) Behavioral rationality as a foundation for public policy studies. Cogn Syst Res 43:63-75

Jones M, Crow D (2017) How can we use the 'science of stories' to produce effective scientific stories? Pal Commun

Kahneman D (2012) Thinking fast and slow (UK edition). Penguin, London

Kam CD (2005) Who toes the party line? Cues, values, and individual differences. Political Behav 27(2):163-182. https://doi.org/10.1007/s11109-005-1764-y

Kapoutsis I, Papalexandris A, Nikolopoulos A, Hochwarter WA, Ferris GR (2011) Politics perceptions as moderator of the political skill - job performance relationship: A two-study, cross-national, constructive replication. J Vocat Behav 78(1):123-135. https://doi.org/10.1016/j.jvb.2010.09.009

Kingdon J (1984) Agendas, alternatives and public policies. Harper Collins, New York, NY

Kwiatkowski R (2011) Politicians and power: MPs in the UK parliament. In Weinberg A (ed) The Psychology of Politicians, Cambridge University Press, Cambridge, 39-58. https://doi.org/10.1017/CBO9781139026482.004

Kwiatkowski R (2016) Mind games. House Mag 8:34-35

Larrick RP (2016) The social context of decisions. Annu Rev Organ Psychol Organ Behav 3:441-467

Lewis P (2013) Policy thinking, fast and slow: a social intuitionist perspective on public policy processes, American Political Science Association 2013 Annual Meeting. SSRN: http://ssrn.com/abstract=2300479

Lewis R, Donaldson-Feilder E (2012) Perspectives on leadership in 2012: implications for HR. http://www.cipd.co.uk/hr-resources/research/perspectivesleadership-2012.aspx

Lindblom C (1959) The science of muddling through. Public Adm Rev 19:79-88

Lindblom C (1964) Contexts for change and strategy: a reply. Public Adm Rev 24 (3):157-8

Lodge M, Taber C (2005) The automaticity of affect for political leaders, groups, and issues. Political Psychol 26(3):455-482

McBeth M, Jones M, Shanahan E (2014) The narrative policy framework. In: Sabatier P, Weible C (eds) Theories of the policy process, 3rd edn. Westview Press, Chicago

Menges JI, Kilduff M (2015) Group emotions: cutting the gordian knots concerning terms, levels ofanalysis, and processes. Acad Manag Ann 9(1):845-928. https://doi.org/10.1080/19416520.2015.1033148

Miller G (1956) The magical number seven, plus or minus two: some limits on our capacity for processing information. Psychol Rev 101(2):343-352. https://doi. org $/ 10.1037 / \mathrm{h} 0043158$ 
Parkhurst J (2016) The politics of evidence: from evidence-based policy to the good governance of evidence. Routledge, London

Perez O (2015) Can experts be trusted and what can be done about it? Insights Biases Heuristics Lit 1:1-32. September 2014

Pielke Jr R (2007) The honest broker: making sense of science in policy and politics. Cambridge University Press, Cambridge

Prati LM, Perrewe PL, Ferris GR (2009) Emotional intelligence as moderator of the surface acting--strain relationship. J Leadersh Organ Stud 15(4):368-380. https://doi.org/10.1177/1548051808328518

Quattrone G, Tversky A (1988) Contrasting rational and psychological analysis of political choice. Am Political Sci Rev 82:719-736

Rock D (2008) SCARF: a brain-based model for collaborating with and influencing others. NeuroLeadership J 1(1):44-52. https://doi.org/10.1109/18.796373

Sabatier P (1998) The advocacy coalition framework: revisions and relevance for Europe. J Eur Public Policy 5(1):98-130

Sabatier P, Hunter S, McLaughlin S (1987) The devil shift: perceptions and misperceptions of opponents. The Western Political Quarterly, 40(3):449-476

Sabatier P, Jenkins-Smith H (eds) (1993) Policy change and learning: an advocacy coalition approach. Westview Press, Boulder, CO

Schein Edgar H (1969) Process consultation: Its role in organization development

Schneider A, Ingram H, deLeon P (2014) Democratic policy design: social construction of target populations In: Sabatier P, Weible C (eds) Theories of the policy process, 3rd edn. Westview Press, Cambridge, MA

Simon H (1957) Models of man: social and rational. John Wiley, New York, NY

Simon H (1976) Administrative behavior, 3rd edn. Macmillan, London

Smith K, Stewart E (2017) Academic advocacy in public health: disciplinary 'duty' or political 'propaganda'?. Social Sci Med 189:35-43. September

Stoker G (2010) Translating experiments into policy. Ann Am Acad Political Social Sci $628: 47-58$

Stone D (1989) Causal stories and the formation of policy agendas. Political Sci Q 104:281-300

Storbeck J, Clore GL (2007) On the interdependence of cognition and emotion. Cogn Emot 21(6):1212-1237. https://doi.org/10.1080/02699930701438020

True JL, Jones BD, Baumgartner FR (2007) Punctuated equilibrium theory. In: Sabatier P(ed) Theories of the Policy Process, 2nd edn. Westview Press, Cambridge, MA

Tuckett D, Nikolic N (2017) The role of conviction and narrative in decisionmaking under radical uncertainty. Theory Psychol 27(4):501-523

Tversky A, Kahneman D (1973) Availability: a heuristic for judging frequency and probability. Cogn Psychol 5:207-32

Van Stekelenburg J, Klandermans B (2013) The social psychology of protest. Curr Sociol 61(5-6):886-905

Weible C (2007) An advocacy coalition framework approach to stakeholder analysis: understanding the political context of California marine protected area policy. J Public Adm Res Theory 17(1):95-117
Weible (2014) Introduction. In: Sabatier P, Weible C (eds) Theories of the policy process. 3rd edn. Westview Press, Cambridge, MA

Weible C, Heikkila T, deLeon P, Sabatier P (2012) Understanding and influencing the policy process. Policy Sci 45(1):1-21

Wildavsky A (1980) The art and craft of policy analysis. MacMillan, London

Winne PH, Nesbit JC (2010) The psychology of academic achievement. Annu Rev Psychol 61(1):653-678. https://doi.org/10.1146/annurev.psych.093008. 100348

Witte Kim, Allen Mike (2000) A meta-analysis of fear appeals: implications for effective public health campaigns. Health Educ Behav 27(5):591-615

Zahariadis N (2014) Pythia's cave: ambiguity and multiple streams In: Sabatier P, Weible C (eds) Theories of the policy process, 3rd edn Westview Press, Cambridge, MA

\section{Data availability}

Data sharing is not applicable to this paper as no datasets were analysed or generated.

\section{Additional information}

Competing interests: The authors declare no competing financial interests.

Reprints and permission information is available online at http://www.nature.com/ reprints

Publisher's note: Springer Nature remains neutral with regard to jurisdictional claims in published maps and institutional affiliations.

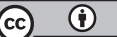

Open Access This article is licensed under a Creative Commons Attribution 4.0 International License, which permits use, sharing, adaptation, distribution and reproduction in any medium or format, as long as you give appropriate credit to the original author(s) and the source, provide a link to the Creative Commons license, and indicate if changes were made. The images or other third party material in this article are included in the article's Creative Commons license, unless indicated otherwise in a credit line to the material. If material is not included in the article's Creative Commons license and your intended use is not permitted by statutory regulation or exceeds the permitted use, you will need to obtain permission directly from the copyright holder. To view a copy of this license, visit http://creativecommons.org/ licenses/by/4.0/.

(C) The Author(s) 2017 